\title{
Paulo Freire na formação de educadores: contribuições para o desenvolvimento de práticas crítico-reflexivas
}

\section{Paulo Freire in teacher training: contributions to the development of critical-reflexive practices}

\author{
Ana Lúcia Souza de Freitas ${ }^{1}$ \\ Mari Margarete dos Santos Forster ${ }^{1}$
}

\begin{abstract}
RESUMO
Paulo Freire é uma referência reconhecida mundialmente. Seu pensamento tem orientado o desenvolvimento de práticas emancipatórias em diferentes campos de atuação. No campo da formação de educadores, sua produção teórica representa importante contribuição para o desenvolvimento de práticas educativas crítico-reflexivas. O texto apresenta uma proposta de ensino/ investigação desenvolvida em um Curso de Mestrado Profissional, como possibilidade de formação de gestores crítico-reflexivos. A metodologia utilizada fundamenta-se em Paulo Freire para propor dispositivos de formação que têm como objetivo o desenvolvimento de conteúdos procedimentais e atitudinais, tais como: a reflexão, o registro, a observação e a escuta. A documentação da experiência de três edições da disciplina Gestão do Ensino Básico foi realizada por meio de diários de pesquisa e outras modalidades de registros reflexivos elaborados pelas/os mestrandas/os. A análise preliminar do material produzido nesta experiência contribuiu para a investigação sobre o tema da gestão escolar, ressignificando o próprio ensino. Da mesma forma, apoiou a compreensão acerca das contribuições de Paulo Freire para o desenvolvimento de práticas educativas crítico-reflexivas no âmbito da docência e da gestão da escola.
\end{abstract}

Palavras-chave: Paulo Freire; formação de educadores; gestão escolar; práticas educativas crítico-reflexivas.

DOI: $10.1590 / 0104-4060.47206$

1 Universidade do Vale do Rio dos Sinos. Programa de Pós-Graduação. Mestrado Profissional em Gestão Educacional. Porto Alegre, Rio Grande do Sul, Brasil. Av. Luiz Manoel Gonzaga, nº 744. CEP: 90.470-280.E-mails: 0311anafreitas@gmail.com e mari.forster@gmail.com 


\begin{abstract}
Paulo Freire is a reference known worldwide. His thought has been guiding the development of emancipatory practices in different areas of work. His theoretical productions represent an important contribution to the development of critical-reflexive teaching practices in the teacher training field. The text shows a teaching/investigation proposal used in a professional Master degree course, as a possibility of a critical-reflexive managers' training. The methodology used is based on Paulo Freire in order to propose training tools that aim to develop procedural and attitudinal contents such as: reflection, records, observation and listening. The experience documentation of the three editions of the subject called Basic Teaching Management, was carried out by research diaries and other ways of reflexive records developed by the graduate students. The first analysis of the material produced in this experience has contributed to the investigation about school management, bringing another meaning for teaching itself. The same way, it has helped to comprehend Paulo Freires' contribution to the development of criticalreflexive teaching practice in the teaching and school management scope.
\end{abstract}

Keywords: Paulo Freire; teacher training; school management; criticalreflexive teaching practices.

\title{
Introdução
}

Escrever, para mim, vem sendo tanto um prazer profundamente experimentado quanto um dever irrecusável, uma tarefa política a ser cumprida. [...] Não escrevo somente porque me dá prazer escrever, mas também porque me sinto politicamente comprometido, porque gostaria de convencer outras pessoas, sem a elas mentir, de que o sonho ou os sonhos de que falo, sobre que escrevo e porque luto, valem a pena ser tentados. (FREIRE, 1994, p. 15-16).

Paulo Reglus Neves Freire, por extenso - ou Paulo Freire, como se tornou conhecido -, é internacionalmente reconhecido como uma referência em diferentes campos de atuação. Apesar disso, com frequência, sua produção teórica é atribuída exclusivamente como contribuição para o campo da educação de jovens e adultos, desconsiderando a amplitude de sua produção. Há também quem considere Paulo Freire ultrapassado; quem faça uso de suas ideias de forma descontextualizada; ou ainda quem empregue suas ideias sem fazer referência 
ao autor. Importa considerar que, por diferentes motivos e de diferentes formas, muitos educadores e educadoras fazem referências a Paulo Freire. Nomeá-lo por extenso tem o objetivo de chamar atenção para a extensão de seu legado, enfatizando a relevância e atualidade de suas contribuições para a formação com educadores/as, na perspectiva da constituição de práticas crítico-reflexivas.

$\mathrm{O}$ texto apresenta uma experiência de ensino/investigação que se fundamenta no pensamento freireano ${ }^{2}$, com vistas à inovação na formação de gestores da Educação Básica no contexto de um Curso de Mestrado Profissional. A escrita está organizada em três partes: inicialmente, apresenta um estudo a respeito do legado de Paulo Freire à formação com educadores, por ser esta a compreensão que fundamenta a experiência em questão; na segunda parte, apresenta o contrato didático que organiza a experiência de ensino/investigação na disciplina Gestão do Ensino Básico, destacando a proposição de dispositivos de formação para o desenvolvimento de práticas crítico-reflexivas; por fim, são considerados os resultados e perspectivas que anunciam a relevância e a atualidade do legado de Paulo Freire para a formação de educadores/as e gestores/as.

\section{O legado de Paulo Reglus Neves Freire à formação com educadores}

Paulo Reglus Neves Freire, ou Paulo Freire, como usualmente nomeado, tornou-se referência no campo da formação de professores para contrapor-se à abordagem tradicional do ensino, denominada por ele de educação bancária. $\mathrm{O}$ autor faz uso da metáfora para expressar sua crítica às relações educacionais verticalizadas, nas quais o educador supostamente deposita o conhecimento na mente dos educandos. (FREIRE, 1987). Para além de um método, Paulo Freire nos deixa como legado uma teoria educacional que nos ensina a perceber a educação num sentido amplo, considerando a totalidade e a complexidade das dimensões que a constituem, ou seja, compreendendo a educação como um ato político (dimensão política), ao mesmo tempo em que também se realiza como uma determinada concepção teórica (dimensão epistemológica) e que mobiliza a inteireza dos sujeitos envolvidos (dimensão estética). (FREITAS, 2001). No campo da formação de professores, sua obra tornou-se referência teórica, sendo a concepção de educação libertadora reconhecida como uma das abordagens do ensino (MIZUKAMI, 1986) e uma das tendências no âmbito da pedagogia progressista. (LIBÂNEO, 1986).

2 Diferente do que indicam as normas ortográficas, a grafia empregada é a sugerida por Ana Maria Freire, mantendo inalterado o nome do autor. 
De modo mais específico, as obras publicadas na década de 1990, após sua experiência como gestor na Secretaria Municipal de Educação de São Paulo, revelam seu legado no âmbito da educação formal. (FREITAS, 2001). No que se refere à formação de educadores/as - ou, numa linguagem freireana, à formação com educadores/as, dada a horizontalidade das relações estabelecidas -, merece destaque a obra Educação na Cidade. Esta publicação reúne entrevistas realizadas no período de sua experiência como gestor, entre elas, a entrevista concedida à professora Ana Maria Saul, da Pontifícia Universidade Católica de São Paulo (PUC-SP), publicada sob o título Autonomia escolar e reorientação curricular. Questionado sobre os programas de atualização de professores realizados em sua gestão como secretário municipal de educação, Paulo Freire responde apresentando, didaticamente, os seis princípios básicos do programa de formação de educadores desenvolvidos na Secretaria; entre eles, "[...] a formação do educador deve instrumentalizá-lo para que ele crie e recrie a sua prática através da reflexão sobre o seu cotidiano". (FREIRE, 1991, p. 80).

Na mesma publicação, sob o título Desafios da Educação Municipal, a entrevista concedida à revista italiana Terra Nuova fala da experiência pessoal, expressando sua compreensão sobre o processo de tornar-se educador, ao afirmar que: "Ninguém começa a ser educador numa certa terça-feira às quatro horas da tarde. Ninguém nasce educador ou marcado para ser educador. A gente se faz educador, na prática e na reflexão sobre a prática”. (FREIRE, 1991, p. 58).

A partir desta obra, sua produção teórica faz referência, de modo mais explícito, aos saberes necessários à prática educativa, reunidos posteriormente na publicação da Pedagogia da Autonomia. Paulo Freire desafia a autoria dos/ as leitores/as à recriação de suas práticas, tematizando o espaço escolar e, desse modo, amplia sua contribuição para o campo da formação com educadores/as.

Todavia, a referência de Paulo Freire torna-se indispensável à formação com educadores e educadoras, sobretudo porque, por meio de sua produção teórica, se faz testemunho do que propõe: a constituição de educadores/as pesquisadores/as. De fato, segundo o autor, o termo expressa uma redundância, por considerar que:

Fala-se hoje, com insistência, no professor pesquisador. No meu entender o que há de pesquisador no professor não é uma qualidade ou uma forma de ser ou de atuar que se acrescente à de ensinar. Faz parte da natureza da prática docente a indagação, a busca, a pesquisa. O que se precisa é que, em sua formação permanente, o professor se perceba e se assuma, porque professor, como pesquisador. (FREIRE, 1996, p. 32). 
A escrita, em forma de narrativa, revela sua experiência de "gestação das ideias" (FREIRE, 1992, p. 53), contribuindo significativamente para que seus leitores/as percebam a natureza investigativa das relações de ensinar e de aprender e se disponham a constituírem-se pesquisadores/as da própria prática. A obra Pedagogia da Esperança é bastante elucidativa sobre o modo como Paulo Freire exerce e propõe que seja exercido o ato de registrar, na perspectiva de que educadores/as se assumam como pesquisadores/as. Narra, com detalhes, o processo que deu origem à Pedagogia do Oprimido.

Comecei a escrever fichas a que ia dando, em função do conteúdo de cada uma, um certo título ao mesmo tempo em que as numerava. Andava sempre com pedaços de papel nos bolsos, quando não com um pequeno bloco de notas. Se uma idéia me ocorria, não importava onde estivesse, no ônibus, na rua, num restaurante, sozinho, acompanhado, registrava a idéia. Às vezes, era uma pura frase. À noite, em casa, depois do jantar, trabalhava a ou as idéias que havia registrado, escrevendo duas, três ou mais páginas. Em seguida, dava o título para a ficha e o número em ordem crescente. (FREIRE, 1996, p. 58).

Freire nos dá o testemunho sobre um intenso processo de produção teórico-crítica a partir da permanente reflexão sobre suas vivências, argumentando que essa produção intelectual não tem um fim em si; a riqueza do processo encontra-se justamente na relação dialética que se estabelece entre escrita e oralidade, entre teoria e prática, na qual a interação assume um caráter fundamental de realimentar o próprio processo de escrita, orientando-a no sentido de novas necessidades. Assim, confidencia que juntou ao hábito de escrever o de compartilhar a escrita com amigos, "[...] discutindo achados e não apenas meus textos, debatendo dúvidas, interrogando-nos, desafiando-nos, sugerindo-nos leituras, surpreendendo-nos". (FREIRE, 1996, p. 52).

A partir de sua experiência, argumenta a favor da necessidade da constituição de espaços coletivos de formação na escola, a fim de que se desenvolvam práticas de observação, registro, reflexão e discussão permanentes. Sugere, aos educadores e educadoras, que, especialmente em seu trabalho com educação popular, tenham a preocupação de ir registrando histórias e retalhos de conversas, frases e expressões oriundas da escuta cotidiana.

O registro, na perspectiva proposta por Freire, integra o ato crítico de estudar (FREIRE, 1982) e representa uma possibilidade do educador/a distanciar-se epistemologicamente de sua própria reflexão para melhor compreendê-la. Para 
ele, o ato de registrar é também uma forma de exercitar a capacidade de observar, desafiando nossas certezas e mobilizando a reflexão. Ou seja, o registro, criticamente exercido, representa um legado do pensamento freireano para orientar o permanente exercício de avaliação e reflexão sobre a prática, tornando a experiência do ensino uma prática de investigação permanente. (FREITAS, 2010).

$\mathrm{Na}$ atualidade, importa considerar que educandos e educadores (trans) formam-se mutuamente nos processos de ensinar e de aprender, perpassados pela pesquisa, e deflagram percursos formativos singulares, mobilizados pela emoção/reflexão que emergem nessa interação. (FREITAS, 2004, 2014). Todavia, ainda que esse seja um processo coletivo, não prescinde do esforço reconstrutivo individual que, embora condicionado por uma multiplicidade de fatores intrínsecos e extrínsecos, tem na experiência do registro um apoio para a constituição de novas autorias.

A elaboração de um tetragrama, apresentado a seguir (Figura 1), é um recurso empregado para elucidar essa compreensão. O tetragrama é um modelo explicativo sugerido por Morin (1990) para expressar a qualidade auto-organizativa das relações estabelecidas entre seus elementos constitutivos, de modo a sugerir o jogo das permanentes formações e transformações estabelecidas entre a ordem, a desordem, a interação e a organização. Parafraseando Morin, o tetragrama é empregado por Freitas (2004) para elucidar a complexidade do processo de (trans)formação permanente em que as relações entre ação, reflexão, emoção e registro tornam-se elementos constitutivos dos processos de ensinar e de aprender.

FIGURA 1 - O TETRAGRAMA DO PROCESSO DE (TRANS)FORMAÇÃO PERMANENTE

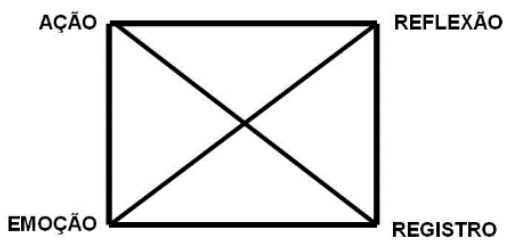

FONTE: Freitas (2004).

O tetragrama da (trans)formação permanente expressa a compreensão sobre a complexidade das relações de ensinar e de aprender e desafia à constituição de práticas crítico-reflexivas. Pode também ser compreendido como uma forma de expressar a atualidade do legado de Paulo Freire à formação 
com educadores/as e uma contribuição para orientar a constituição de propostas inovadoras. Espera-se, sobretudo, que seja reconhecida, como um dos legados de Paulo Freire, a experiência da escrita exercida como uma forma de luta por sonhos possíveis; sua obra consiste em fonte inesgotável de consulta e permanente convite à sua atualização e recriação. É neste sentido que se apresenta, a seguir, o registro sobre a reflexão de uma experiência em processo.

\section{Paulo Freire na formação de gestores: uma experiência de inovação no Curso de Mestrado Profissional}

O Curso de Mestrado Profissional em Gestão Educacional, em funcionamento desde 2013 na Universidade do Vale do Rio dos Sinos (UNISINOS), tem desafiado a todos os que atuam na gestão, na docência e na discência do Programa à constituição de uma proposta inovadora. Em consonância com o desafio proposto no projeto do Curso, a experiência na disciplina Gestão do Ensino Básico, com base no pensamento freireano, vem contribuindo para a inovação no âmbito da formação de gestores.

A disciplina tem oferta anual e integra os créditos obrigatórios vinculados à linha de pesquisa Gestão Escolar e Universitária. Assim como outras disciplinas do curso, é ministrada na modalidade de docência compartilhada, sendo este um aspecto potencialmente inovador, considerando a concepção de inovação como ruptura, como propõe Elisa Lucarelli (2009):

Categorizar a la innovación como ruptura implica entenderla como la interrupción de una determinada forma de comportamiento que se repite en el tiempo y que se legitima, dialécticamente, con la posibilidad de relacionar esta nueva práctica con las existentes a través de mecanismos de oposición, diferenciación o articulación. (LUCARELLI, 2009, p. 52).

A docência realizada mediante o compartilhamento das experiências de duas professoras, doutoras em educação, em permanente diálogo na gestão da aula universitária, fortalece as iniciativas individuais quanto à realização de práticas que propõem a ruptura com a concepção de educação bancária (FREIRE, 1987), contrariando as expectativas convencionais acerca das relações de ensinar e de aprender. A partir da docência compartilhada vêm sendo ampliadas 
as condições para assumir a complexidade das relações de ensinar, aprender e pesquisar, na perspectiva freireana, de que "Ensinar não é transferir conhecimento, mas criar as possibilidades para a sua produção ou a sua construção". (FREIRE, 1996, p. 25), ou seja, de contrariar o senso comum acerca da aula e da função do professor, como propõe Terezinha Rios (2001, p. 27): “[...] a aula não é algo que se dá, mas que se faz, no trabalho conjunto de professores e alunos".

Ainda que a intenção de ruptura com a educação bancária não seja nova, inscreve-se em novos desafios diante do cenário em que as Tecnologias de Informação e Comunicação (TICs) parecem sugerir práticas inovadoras mesmo quando, em algumas situações, apenas operacionalizam uma melhora incremental da educação bancária. (MORAES et al., 2015, 2013; FREITAS; LEITE; LIMA, 2012). Todavia, "[...] numa ruptura é sempre fruto de um processo e assim precisa ser analisada" (LEITE; LUCARELLI; VEIGA, 1999, p. 67); não se dá de um instante para o outro, mas se constrói por meio de uma trajetória individual, vivida no coletivo e, por isso, é única para cada indivíduo e para cada grupo. Trata-se de um processo complexo, pois não ocorre do mesmo jeito, do mesmo modo, na mesma intensidade, tão pouco no mesmo momento com todas as pessoas, mesmo que envolvidas em um único processo institucional. Por isso, a experiência da docência compartilhada, com base no diálogo, cria condições para a inovação na sala de aula.

Essa compreensão tem orientado a experiência na disciplina Gestão do Ensino Básico, cuja intenção é a de contribuir para a qualificação do percurso formativo dos/as mestrandos/as na perspectiva da pesquisa com intervenção, inerente ao Curso de Mestrado Profissional. Para tanto, as ações de ensino se organizam a partir de um contrato didático (GRILLO, 2008) que convida os/as mestrandos/as para que vivenciem os momentos do ciclo da pesquisa em sala de aula - o questionamento, a argumentação e a comunicação. (MORAES; LIMA, 2012). Com este intuito, o aprofundamento de estudos sobre a gestão do ensino básico se realiza mediante o desenvolvimento de práticas crítico-reflexivas, tendo em vista sua recriação no âmbito da gestão da escola.

O estudo teórico dos temas - a escola no contexto da transição paradigmática (SANTOS, 1997, 2009); gestão escolar, qualidade do ensino e inovação (ALARCÃO, 2001); gestão, docência e os desafios do ensino no mundo contemporâneo - é complementado pela análise crítica da realidade, incluindo o trabalho de campo em uma escola para enfatizar o diálogo entre teoria e prática no enfrentamento dos desafios da gestão escolar. Partindo da elaboração de um questionamento instigante sobre a gestão do ensino básico, os grupos, constituídos por interesse temático, realizam o aprofundamento de estudos, considerando três fontes de diálogo: o diálogo com a bibliografia de referência; o diálogo com os dados de realidade obtidos no trabalho de campo; e o diálogo 
com a reflexão pessoal (no grupo). Como trabalho final, além de elaborar um resumo com 500 palavras, cada grupo compartilha sua experiência investigativa apresentando o questionamento elaborado, argumentando teórica e praticamente o tema desenvolvido e comunicando suas compreensões acerca dos desafios à gestão do ensino básico.

Esse contrato didático fundamenta-se em Paulo Freire para o desenvolvimento de uma rigorosidade metódica (FREIRE, 1996) que se organiza em função de quatro compromissos: o compromisso com o coletivo, o compromisso com a reflexão, o compromisso com a leitura/escrita e o compromisso com a construção de conceitos. (FREITAS, 2008). Para tanto, propõe dispositivos de formação que convidam à atitude investigativa, com base nos conceitos de reflexão, registro, observação e escuta. A elaboração de diários de aula (ou também nomeados como diários de pesquisa) e de memórias de aula, embora com proposições distintas, têm em comum a intenção de problematizar as relações de ensinar e de aprender e apoiar a pesquisa em sala de aula, de modo a contribuir para o desenvolvimento de práticas crítico-reflexivas.

Para a elaboração do diário de pesquisa em sala de aula é solicitado que, além das usuais anotações, relacionadas ao conteúdo abordado, sejam incluídos registros de reflexão pessoal: impressões, emoções, comentários, questionamentos, relações estabelecidas, entre outros. Além de registrar a observação/reflexão da experiência de sala de aula, o diário ganha significado quando utilizado no trabalho de campo realizado em uma escola. Na continuidade, a leitura do diário pelo educador/a, com a realização de apontamentos, transforma-o em instrumento de diálogo mediado pela escrita.

De igual modo, a proposição das memórias de aula convida ao registro reflexivo sobre a experiência, desde a perspectiva de quem escreve. A cada encontro, uma dupla ou trio de estudantes se voluntaria para a elaboração da memória de aula a ser compartilhada com os colegas. Na orientação para a escrita, importa enfatizar a intenção de ser um registro reflexivo e, neste sentido, espera-se que não se restrinja à cópia de tópicos e reflexões apresentados, mas inclua a reflexão de quem escreve, assim como promova a reflexão dos interlocutores a quem se dirige. Trata-se de se permitir a ir além das anotações sobre o conteúdo abordado, incluindo provocações para o compartilhamento da reflexão. Assim, as memórias de aula tornam-se um diário coletivo, cujas produções elaboradas são tomadas como ponto de partida de cada aula, fazendo da leitura inicial um processo reflexivo de retomada das discussões anteriormente realizadas, orientando a continuidade dos estudos. Por meio dos diários de pesquisa e das memórias de aula se operacionaliza o registro sistemático (FREITAS, 2010), como um instrumento de reflexão sobre a prática, favorecendo a documentação da experiência do ensino e criando condições para a pesquisa. 
Assim, a inovação da sala de aula, com base no pensamento freireano, põe em diálogo duas perspectivas complementares: ensinar a pesquisa e pesquisar o ensino, caracterizando-se como um movimento de formação e de transformação permanente e revelando possibilidades de maximizar o potencial emancipatório das relações de ensinar e de aprender. (FREITAS, 2004, 2014). No contexto da formação de gestores no Mestrado Profissional, a relevância dessa experiência diz respeito ao fortalecimento da compreensão de que a gestão do ensino básico, simultaneamente assumida como tema de ensino e de pesquisa, pode incentivar ações colaborativas e potencializar a ruptura com práticas de educação bancária na escola e na universidade.

\section{Resultados e perspectivas}

A realização da experiência da docência compartilhada em três edições consecutivas da disciplina Gestão do Ensino Básico ${ }^{3}$, com a permanência das mesmas docentes, viabilizou a avaliação em processo e o aperfeiçoamento das proposições que hoje se apresentam, tendo em vista a formação de gestores crítico-reflexivos.

As duas primeiras turmas elaboraram diários de pesquisa e realizaram um trabalho de campo em uma escola pública ${ }^{4}$; a terceira turma elaborou memórias de aula e contou com a participação da direção de uma das escolas visitadas anteriormente para o relato de sua experiência de gestão ${ }^{5}$. A análise dos registros de documentação da experiência permitiu realizar a avaliação em processo, servindo de orientação para o planejamento de cada nova edição da disciplina. Além dos diários e memórias de aula, a cada semestre foram analisados também os registros referentes à avaliação da disciplina e à autoavaliação realizada pelos/ as mestrandos/as, proporcionando compreensões que tanto contribuem para o aperfeiçoamento desta proposição de ensino/pesquisa, quanto sugerem temas relevantes para a formação de educadores e gestores escolares.

3 No período de 2013 a 2015.

4 A turma de 2013 visitou a Escola Municipal de Educação Básica, Clodovino Soares, no município de Esteio/RS; a turma de 2014 visitou a Escola Estadual de Ensino Médio Cônego José Leão Hartmann, no município de Canoas/RS.

5 Relato realizado pela diretora da Escola Estadual de Ensino Médio Cônego José Leão Hartmann, professora $\mathrm{Dr}^{\mathrm{a}}$ Rosane Duarte de Oliveira Zimmer, contando também com a participação e o depoimento de uma estudante do ensino médio da mesma escola, Luelen Santana Moura. 
No que se refere às contribuições para o ensino, destaca-se a importância do diálogo com a experiência da escola, realizado entre as atividades curriculares, visto que ampliou a compreensão acerca dos desafios à gestão escolar. Permitiu vislumbrar a diversidade dos temas relacionados à gestão no cotidiano escolar, os quais foram sendo progressivamente incorporados aos eixos temáticos propostos na disciplina. Entre eles, as políticas de acesso e inclusão, o uso de recursos tecnológicos para a promoção da aprendizagem, a relação com a comunidade escolar, as avaliações externas e a formação continuada na escola.

$\mathrm{Na}$ avaliação da disciplina realizada pelos/as mestrandos/as, a relação com a escola é referida em função de sua contribuição para a articulação entre teoria e prática. Nas palavras de um/a estudante, o diálogo com a experiência da escola foi importante porque permitiu compreender que "[...] a Gestão do Ensino Básico não é uma tarefa fácil/simples [...] levando em conta problemas e situações reais". Todavia, ao se referir ao relato de experiência em sala de aula, outro/a mestrando/a afirmou que:

[...] foi uma ótima oportunidade de conhecer a gestão de uma escola e debater a gestão do Ensino Básico de maneira tão abrangente e informal; todavia, a "aula" foi tão descontraída que perdeu um pouco o caráter acadêmico para o qual se propunha, na medida em que, critérios mais cientificos deram lugar a fotos e vídeos em situações ditas "rotineiras".

A insatisfação manifestada no instrumento de avaliação revelou um posicionamento não apresentado no diálogo favorecido durante o processo, o que reforça a necessidade de dar continuidade à experiência de ensino/pesquisa, ampliando a escuta dos/as mestrandos/as e tensionando suas concepções educativas.

Os procedimentos metodológicos relacionados ao registro também foram referidos na avaliação da disciplina, de um modo geral, como um aspecto positivo, mesmo quando mencionadas as dificuldades de sua realização. Na avaliação do trabalho com as memórias de aula, $50 \%$ dos estudantes fizeram referências positivas ao procedimento. Além disso, alguns comentários expressam os significados atribuídos à experiência: " $A$ vivência da escrita foi fundamental e principalmente inovadora. Infelizmente produzimos muito na prática e pouco ou quase nada relatamos ou descrevemos". Outro/a estudante sugere que "[...] a construção de memórias poderia ser retomada como discussão final, tendo em vista que a sua construção [...] acaba se tornando, na Gestão de instituições educacionais, apenas um instrumento burocrático, no meio de outros tantos ins- 
trumentos, sem sua devida reflexão". A sugestão apresentada revela compreensão sobre as possibilidades de recriação da experiência no âmbito da gestão escolar.

Em síntese, os procedimentos utilizados, com base no pensamento de Paulo Freire, operacionalizaram o ensino/pesquisa evidenciando as seguintes contribuições: favoreceram a abordagem teórico-prática para o estudo dos temas; ampliaram o diálogo entre as educadoras e os/as mestrandos/as; e oportunizaram a realização de práticas crítico-reflexivas.

Entre os aspectos emergentes na avaliação da disciplina, chamou atenção a recorrência dos comentários de satisfação relacionados ao clima favorável ao estudo proporcionado pela docência compartilhada, referindo, de diferentes formas, "a sintonia das duas professoras", marcada pelo diálogo e pela reflexão coletiva. Isso pode ser um indicativo do diferencial que se revela com essa modalidade de ensino, sugerindo contribuições à pesquisa acerca dos impactos da docência compartilhada nas relações de ensinar e de aprender.

No que se refere às contribuições para a pesquisa, destaca-se o conteúdo suscitado pelo instrumento de autoavaliação. Os/as mestrandos/as fazem referência, de modo recorrente, às aprendizagens relacionadas ao desenvolvimento da atitude reflexiva que, em algumas situações, realizou-se como uma experiência nova, influenciando a disposição para a aprendizagem e a qualidade das aprendizagens conceituais. Os depoimentos de autoavaliação também anunciam outras repercussões das ações de ensino intencionadas para o desenvolvimento de práticas crítico-reflexivas. Entre elas, o modo como o processo reflexivo desencadeado mobilizou a emoção dos/as mestrandos/as, influenciando em sua disposição à aprendizagem. Essa percepção corrobora com a compreensão de Solé (2006) acerca da indissociabilidade entre os aspectos cognitivos e os aspectos afetivo-relacionais, sugerindo novas possibilidades de investigação.

Enfim, os aspectos aqui referidos tanto apresentam desafios às relações de ensinar e de aprender, quanto sugerem focos de investigação relevantes à formação de gestores educacionais, sobretudo, à continuidade da experiência da docência compartilhada, tendo em vista o desenvolvimento de práticas crítico-reflexivas na formação de gestores. Os desafios que se apresentam neste momento se inscrevem na perspectiva da consolidação de práticas de ensino inovadoras, com base no pensamento freireano. Nessa perspectiva, para além da necessidade de mensuração, educadores e gestores escolares não podem negar o risco, mas, ao contrário, precisam assumi-lo e aprender a lidar e agir competentemente diante de sua inevitabilidade. Se, como nos ensina Freire, o risco consiste num fator intrínseco ao ato de aprender e não há educação sem o envolvimento da subjetividade dos sujeitos (FISCHER; LOUSADA, 2010), justifica-se a necessidade da pesquisa como apoio à compreensão da complexidade dos processos educativos, tendo em vista a inovação do/no ensino. 
Dar continuidade a essa experiência de ensino/investigação, articulando o tema da gestão do ensino básico com diferentes contextos escolares é um desafio que se apresenta para o aprofundamento de estudos na disciplina. Da mesma forma, é importante considerar os limites de um componente curricular e a necessidade de sua articulação com outras experiências em andamento no Curso.

Ao finalizar, recorrendo a Freire (1991, p. 7), ratificamos a compreensão de que "mudar é difícil, mas é possível e urgente". Assumir desafio de tamanha complexidade requer ampliar parcerias e estabelecer novas interlocuções. Este é o convite que fazemos com o compartilhamento dessa experiência.

\section{REFERÊNCIAS}

ALARCÃO, I. (Org.). Escola reflexiva e nova racionalidade. Porto Alegre: Artmed Editora, 2001.

FISCHER, N. B.; LOUSADA, V. L. Risco (verbete). In: STRECK, D.; REDIN, E.; ZITKOSKI, J. J. (Org.). Dicionário Paulo Freire. 2. ed. rev. amp. Belo Horizonte: Autêntica Editora, 2010. p. 363-364.

FREIRE, P. Considerações em torno do ato crítico de estudar. In: FREIRE, P. Ação Cultural para a Liberdade e outros escritos. 6. ed. Rio de Janeiro: Paz e Terra, 1982. p. 9-12.

FREIRE, P. Pedagogia do Oprimido. 22. ed. Rio de Janeiro: Paz e Terra, 1987.

FREIRE, P. A Educação na Cidade. São Paulo: Cortez, 1991.

FREIRE, P. Pedagogia da Esperança: um reencontro com a Pedagogia do Oprimido. Rio de Janeiro: Paz e Terra, 1992.

FREIRE, P. Cartas à Cristina. Rio de Janeiro: Paz e Terra, 1994.

FREIRE, P. Pedagogia da Autonomia: saberes necessários à prática educativa. São Paulo: Paz e Terra, 1996.

FREIRE, P. Pedagogia da Indignação: cartas pedagógicas e outros escritos. São Paulo: Editora UNESP, 2000.

FREITAS, A. L. S. de. Pedagogia da conscientização: um legado de Paulo Freire à formação de professores. Porto Alegre: EdiPUCRS, 2001.

FREITAS, A. L. S. de. Pedagogia do inédito-viável: contribuições da participação pesquisante em favor de uma política pública e inclusiva de formação com educadores e educadoras. Tese (Doutorado em Educação) - Pontifícia Universidade Católica do Rio Grande do Sul, Porto Alegre, 2004. 
FREITAS, A. L. S. de. Diário de Aula. In: LIMA, V. M. do R.; FREITAS, A. L. S. de.; GRILLO, M. C.; GESSINGER, R. M. A gestão da aula universitária na PUCRS. Porto Alegre: EdiPUCRS, 2008. p. 119-130.

FREITAS, A. L. S. de. Registro (verbete). In: STRECK, D.; REDIN, E.; ZITKOSKI, J. (Org.). Dicionário Paulo Freire. 2. ed. rev. amp. Belo Horizonte: Autêntica Editora, 2010. p. 355-356.

FREITAS, A. L. S. de. Leituras de Paulo Freire: uma trilogia de referência. Passo Fundo: Méritos, 2014. v. 1.

FREITAS, A. L. S.; LEITE, L. L.; LIMA, V. M. do R. (Org.). Ensinar e Aprender com TICs: práticas de capacitação docente na PUCRS. Porto Alegre: EdiPUCRS, 2012. v. 1.

GRILLO, M. C.; FREITAS, A. L. S. de; GESSINGER, R. M.; LIMA, V. M. do R. (Org.). A gestão da aula universitária na PUCRS. Porto Alegre: EdiPUCRS, 2008.

LEITE, D.; LUCARELLI, E.; VEIGA, I. Inovação como fator de revitalização do ensinar e do aprender na universidade. In: LEITE, D. (Org.). Pedagogia Universitária: conhecimento, ética e política no ensino superior. Porto Alegre: Ed. Universidade/ UFRGS, 1999. p. 63-78.

LIBÂNEO, J. C. Democratização da Escola Pública: a Pedagogia Crítico-Social dos Conteúdos. São Paulo: Ed. Loyola, 1986. (Coleção Educar).

LUCARELLI, E. Teoría y práctica en la universidad: la innovación en las aulas. Buenos Aires: Miño y Dávila Editores, 2009. (Colección Educación, Crítica \& Debate).

MIZUKAMI, M. da G. N. Ensino: as Abordagens do Processo. São Paulo: EPU, 1986.

MORAES, M. C.; LEITE, L. L.; GESSINGER, R. M.; FREITAS, A. L.; LIMA, V. M. R. LabTEAR: uma experiência de aplicação dos princípios da mediação pedagógica na aula universitária. LACLO 2011, v. 4, p. 01-06, 2013.

MORAES, M. C.; LEITE, L. L.; LUZ DIAS, R. da; ELIZABETH, A.; FIGUEIREDO, P. L.; GESSINGER, R. M.; NUNES, C. M. LabsMóveis: innovation in the University Classroom through Mobile Devices. In: ROCHA, A.; CORREIA, A. M.; COSTANZO, S.; REIS, L. P. (Org.). Advances in Intelligent Systems and Computing. Switzerland: Springer International Publishing, 2015. p. 1183-1191.

MORAES, R.; LIMA, V. M. do R. (Org.). Pesquisa em sala de aula: tendências para educação em novos tempos. 3. ed. Porto Alegre: EdiPUCRS, 2012.

MORIN, E. Ciência com consciência. Portugal: Publicações Europa-América Ltda., 1990.

RIOS, T. Compreender e ensinar: por uma docência da melhor qualidade. São Paulo: Cortez, 2001.

SANTOS, B. de S. Um discurso sobre as ciências. 9. ed. Portugal: Afrontamento, 1997. 
SANTOS, B. de S. Para uma Pedagogia do Conflito. In: FREITAS, A. L. S. de; MORAES, S. C. de (Org.). Contra o desperdício da experiência: a Pedagogia do Conflito revisitada. Porto Alegre: Redes Editora, 2009. p. 15-40.

SOLÉ, I. Disponibilidade para a aprendizagem e sentido da aprendizagem. In: COLL, C.; MARTÍN, E.; MAURI, T.; MIRAS, M.; ONRUBIA, J.; SOLÉ, I.; ZABALA, A. $O$ construtivismo na sala de aula. São Paulo: Ática, 2006.

Texto recebido em 16 de junho de 2016. Texto aprovado em 16 de junho de 2016. 
